\title{
DESIGN PARA INCLUSÃO: REQUISITOS PARA UM APARELHO AUDITIVO COMO ACESSÓRIO DE MODA
}

\section{DESIGN FOR INCLUSION: PROJECT REQUIREMENTS TO AN HEARING AID AS A FASHION ACCESSORY}

\author{
Julia Marina Cunha ${ }^{1}$ \\ Giselle S. A. D. Merino ${ }^{2}$, Dra. \\ Eugenio A. D. Merino ${ }^{3}$, Dr.
}

(1) Graduanda em Design- Universidade Federal de Santa Catarina (UFSC)

e-mail: juliamarinac@gmail.com

(2) Universidade Federal de Santa Catarina (UFSC) e Universidade Estadual de Santa Catarina (UDESC)

e-mail: gisellemerino@gmail.com

(3) Universidade Federal de Santa Catarina (UFSC)

e-mail: eugenio.merino@ufsc.br

Design inclusivo, aparelho auditivo, estigma.

Esta pesquisa tem como objetivo o desenvolvimento de requisitos de projeto para um aparelho auditivo com

direcionamento estético formal para distanciamento do estigma de tecnologia assistiva; visando melhorar a autoestima e qualidade de vida dos usuários e a utilizando-se dos princípios da ergonomia e design para inclusão, saúde e bem-estar dos seres humanos.

Inclusive design, hearing aid, stigma

This project aims to develop project requirements to an hearing aid with aesthetic guidance that distances itself from the stigma of an assistive technology; aiming to improve the user's self-esteem and quality of life and by using the principles of ergonomics and design for inclusion, health and well-being. 
$16^{\circ}$ Ergodesign - Congresso Internacional de Ergonomia e Usabilidade de Interfaces Humano Tecnológica: Produto, Informações Ambientes Construídos e Transporte

$16^{\circ}$ USIHC - Congresso Internacional de Ergonomia e Usabilidade de Interfaces Humano Computador

CINAHPA | 2017 - Congresso Internacional de Ambientes Hipermídia para Aprendizagem.

\section{Introdução}

A relação dos seres humanos com o ambiente se dá por meio dos sentidos; tato, visão, olfato, audição e paladar. No entanto, é a audição que nos permite a captação dos sons, sendo essencial para a aquisição da linguagem e a comunicação entre os seres humanos.

A perda auditiva está entre as deficiências crônicas mais comuns, e pode ocorrer por diversos fatores, congênita ou adquirida.

Os estudos em Tecnologia Assistiva (TA) vêm ganhando evidência nos últimos anos, em virtude da ascensão dos paradigmas de inclusão social e valorização da diversidade

[RODRIGUES; ALVES, 2013], o que ocorre também devido ao gradativo envelhecimento da população associado à maior expectativa de vida [COLEMAN].

Sendo a tecnologia assistiva socialmente interpretada como um facilitador em um meio incapacitante [DINIZ, 2007], o aparelho auditivo, classificando-se como uma, facilita a comunicação e inclusão de deficientes auditivos.

A tecnologia assistiva pode ser definida como uma esfera do conhecimento interdisciplinar que envolve produtos, recursos, metodologias, práticas e serviços que possuem como objetivo promover a funcionalidade de pessoas com deficiência ou incapacidade, oferecendo bem estar, autonomia e qualidade de vida [BRASIL, Comitê de ajudas técnicas, 2009]. O design, juntamente com a ergonomia, envolve-se no projeto de tecnologias assistivas partindo da relação da pessoa com deficiência e o objeto assistivo, buscando projetar produtos que satisfaçam as necessidades e desejos do ser humano.

Considerando a deficiência como parte constitutiva da identidade individual e consequentemente a Tecnologia Assistiva o reflexo da mesma, nesta pesquisa em específico procura-se inserir o design e a ergonomia de forma a gerar uma imagem positiva para o aparelho auditivo, diminuindo e até eliminando o estigma existente em torno da mesma. Assim, questionando o padrão estabelecido de invisibilidade/camuflagem apresentado pelos produtos existentes e direcionando o projeto de um aparelho auditivo como um acessório.

Pontua-se, portanto, a problemática da pesquisa:

- Quais os requisitos de um aparelho auditivo que se distancie do estigma de tecnologia assistiva, associando-se aos atributos de um acessório de moda?

Como objetivo geral da pesquisa tem-se :

A definição de requisitos de projeto para o desenvolvimento de um aparelho auditivo com direcionamento estético formal do produto como acessório de moda. Especificamente:

a. Compreender a relação dos deficientes auditivos com o aparelho auditivo.

b. Analisar a atuação do design e da ergonomia em projetos de Tecnologias Assistivas.

c. Identificar e pontuar possíveis melhorias funcionais e ergonômicas no aparelho auditivo.

d. Definir requisitos para o projeto de um aparelho auditivo sem estigmas estéticos.

\section{Procedimentos metodológicos}

Considerando a caracterização geral da pesquisa, quanto a natureza pode ser configurada como teórico-aplicada, em relação ao conteúdo, pode ser classificado como artigo de análise onde os elementos são analisados em relação ao todo [MARCONI, 2003].

Referente aos objetivos, a pesquisa pode ser caracterizada como exploratória, constituindo 
$16^{\circ}$ Ergodesign - Congresso Internacional de Ergonomia e Usabilidade de Interfaces Humano Tecnológica: Produto, Informações Ambientes Construídos e Transporte

$16^{\circ}$ USIHC - Congresso Internacional de Ergonomia e Usabilidade de Interfaces Humano Computador

CINAHPA | 2017 - Congresso Internacional de Ambientes Hipermídia para Aprendizagem.

um aprimoramento de ideias sobre o assunto em questão [GIL, 2002]. De acordo com os procedimentos técnicos, caracteriza-se como pesquisa bibliográfica, [GIL, 2002].

Divide-se a pesquisa em duas etapas principais:

Fundamentação teórica: etapa teórica onde apresenta-se a fundamentação, com relação aos métodos pode- se descrever, pesquisas em bases de dados, utilizando as seguintes palavras-chave e as correspondentes em inglês: audição, perda auditiva, aparelho auditivo, ergonomia, tecnologia assistiva, estigma e combinações das mesmas.

Pesquisa aplicada: etapa aplicada onde tem-se o desenvolvimento por meio de análise das informações coletadas. Esta etapa é subdividida em 3 momentos, de acordo com o Guia de Orientação para o Desenvolvimento de Projetos [MERINO, 2014].

O GODP apresenta uma metodologia configurada por oito etapas que se fundamentam na coleta de informações pertinentes ao desenvolvimento da proposta, ao

desenvolvimento criativo, a execução projetual, a viabilização e verificação final do produto.

Estas etapas estão distribuídas em 3 momentos:

Inspiração: Identificação da oportunidade, análise da problemática e levantamento de dados.

Ideação: Neste momento definem-se os requisitos de projeto, estes foram determinados de acordo com os fatores de risco identificados na revisão bibliográfica e desenvolvimento, e divididos em três blocos de informação (produto, usuário e contexto) de acordo com Merino (2014).

Implementação: Especificação e materialização, verificação e testes.

Para os fins desta pesquisa em específico, foram desenvolvidos os métodos apenas dos momentos Inspiração e Ideação, até a obtenção dos requisitos de projeto.

\section{Fundamentação Teórica}

\subsection{Audição e Aparelho Auditivo}

A audição é uma das principais capacidades sensoriais do ser humano, é a consciência da vibração interpretada como som.

A deficiência auditiva é considerada uma das incapacidades mais inabilitantes devido a interferência da mesma na comunicação verbal.

O aparelho auditivo, ou Aparelho Amplificador Sonoro Individual (AASI) é definido como um dispositivo que amplifica a intensidade dos sons no ouvido do utente. É utilizada por deficientes auditivos com perda parcial, uma vez que para sua eficácia devem existir ainda células funcionais na orelha interna do indivíduo.

O aparelho auditivo pode ser classificado em 4 principais categorias ou modelos.

O aparelho retroauricular possui os componentes eletrônicos conectados ao molde por meio de um tubo, é geralmente utilizada por crianças e adolescentes por permitir a substituição constante do molde acompanhando o crescimento da orelha, podendo ser utilizada por pessoas de diversas faixas etárias com perda auditiva de leve à severa [NIDCD, 2016].

O aparelho intra auricular se ajusta completamente à orelha externa e pode ser utilizada por pessoas com perda auditiva leve à severa, nesta os componentes eletrônicos ficam localizados dentro do próprio molde [NIDCD, 2016].

Já os aparelhos intra e micro canal quando colocadas encaixam-se no canal auditivo do usuário. Estas oferecem relativamente maior dificuldade para ajuste pelo próprio utente e não 
$16^{\circ}$ Ergodesign - Congresso Internacional de Ergonomia e Usabilidade de Interfaces Humano Tecnológica: Produto, Informações Ambientes Construídos e Transporte

$16^{\circ}$ USIHC - Congresso Internacional de Ergonomia e Usabilidade de Interfaces Humano Computador

CINAHPA | 2017 - Congresso Internacional de Ambientes Hipermídia para Aprendizagem.

são recomendadas para crianças ou indivíduos com perda auditiva de grau severo, uma vez que as características físicas do produto limitam a potência do aparelho [NIDCD, 2016].

Considerando as informações apresentadas e o objetivo da pesquisa, o modelo escolhido para estudo é o retroauricular, por conta de suas propriedades formais e dimensionais, sendo este o que possui maior visibilidade durante o uso e é possível de utilização por uma parcela mais abrangente de deficientes auditivos, tanto em faixa etária quanto nível de perda auditiva.

Os modelos são apresentados na figura a seguir (Figura 2), em destaque o modelo retroauricular, objeto da pesquisa.
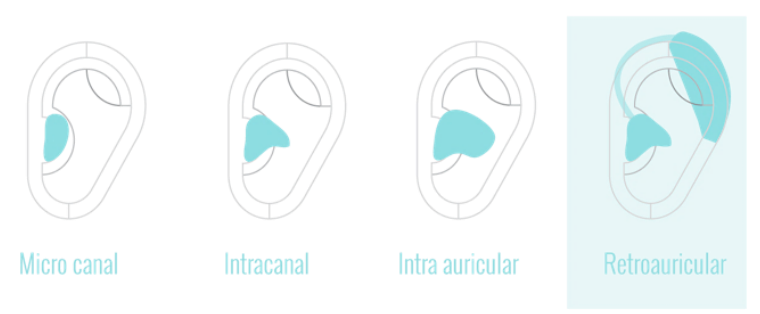

Figura 1- Modelos de aparelho auditivo

Fonte: A autora com base em Frota (2009)

\subsection{Ergonomia e Tecnologia Assistiva}

A ergonomia como disciplina desempenha um papel fundamental no desenvolvimento de um produto inclusivo, uma vez que esta é definida como o estudo da interação entre o ser humano e os demais elementos em um sistema [IEA, 2000].

Não tratando apenas apenas das características físicas da relação homem-objeto, mas também dos valores subjetivos gerados à partir dessa interação. Segundo a abordagem da ergonomia holística, privilegia-se o todo em detrimento das partes, ou seja, os aspectos cognitivos devem ser igualmente considerados [CALDWELL, 2009].
Observando ainda esta relação, dentro dos aspectos subjetivos da interação ser humano/objeto, destaca-se especificamente o conforto em suas variações.

Considerado um estado de bem-estar físico e mental, o conforto é descrito por diversos autores como um sentimento ou uma sensação [MUSSI, 1996], portanto um valor qualitativo.

Este envolve as reações fisiológicas geradas por estímulos do produto, neste caso aparelho auditivo, e do ambiente; assim como o processo psicológico decorrentes dos estímulos sensoriais do meio [LUCAS, 2010]. É recorrente durante o projeto de tecnologias assistivas a carência de consideração do ambiente social vivido pelo indivíduo [PULLIN, 2009].

Clarkson et al (2003) propõe que ao considerar a deficiência uma experiência pela qual todos os indivíduos passam no decorrer da vida; e não uma característica exclusiva de um grupo isolado da sociedade; humaniza-se a deficiência, permitindo considerar aspectos psicológicos e emocionais além dos puramente físicos.

\section{Pesquisa Aplicada}

\subsection{Momento inspiração}

Analisando as informações apresentadas durante a fundamentação teórica e como parte do momento inspiração, procura-se relacionar os tópicos abordados de acordo com os blocos de referência do produto, usuário e contexto [MERINO, 2014]. Sendo produto o resultado do projeto, neste caso o aparelho auditivo. $\mathrm{O}$ usuário sendo o centro do projeto, são todos aqueles que se utilizarão do produto. E contexto sendo o meio onde acontece a interação, onde estão inseridas as demais variáveis.

O design inclusivo e particularmente o design de tecnologias assistivas desempenham um papel crucial para a inclusão social e o bem-estar emocional dos indivíduos, sendo, portanto, 


\section{$16^{\circ}$}

ERGODESIGN USIHC CINAHPA

fundamental a compreensão de todos os aspectos da relação entre os usuários e, neste caso em específico, o aparelho auditivo.

Considerando o objetivo da pesquisa, da abordagem do aparelho auditivo como acessório de moda, destaca-se principalmente a relação do corpo com o produto, assim como a relação do conjunto com a sociedade.

"O corpo é considerado o primeiro veículo de comunicação e expressão utilizado pelo ser humano para produção, reflexão e análise do conhecimento" [GARDIN, 2008]

Segundo Gardin [2008], desde a antiguidade o corpo assume o papel de meio de comunicação, consequentemente a moda é linguagem, um sistema construído de signos que indicam uma forma de expressão.

Os valores da cultura da moda a serem incorporados no projeto de tecnologias assistivas não devem necessariamente estar ligados a tendências em constante mutação, mas sim à promoção da imagem positiva e melhora na autoestima dos usuários.

\subsection{Momento ideação}

Neste momento são apresentados os requisitos de projeto, gerados a partir das informações coletadas durante a pesquisa e segmentados a partir dos blocos de referência, produto, usuário e contexto (Figura 3 ). $16^{\circ}$ Ergodesign - Congresso Internacional de Ergonomia e Usabilidade de Interfaces Humano Tecnológica: Produto, Informações Ambientes Construídos e Transporte

$16^{\circ}$ USIHC - Congresso Internacional de Ergonomia e Usabilidade de Interfaces Humano Computador

CINAHPA | 2017 - Congresso Internacional de Ambientes Hipermídia para Aprendizagem.
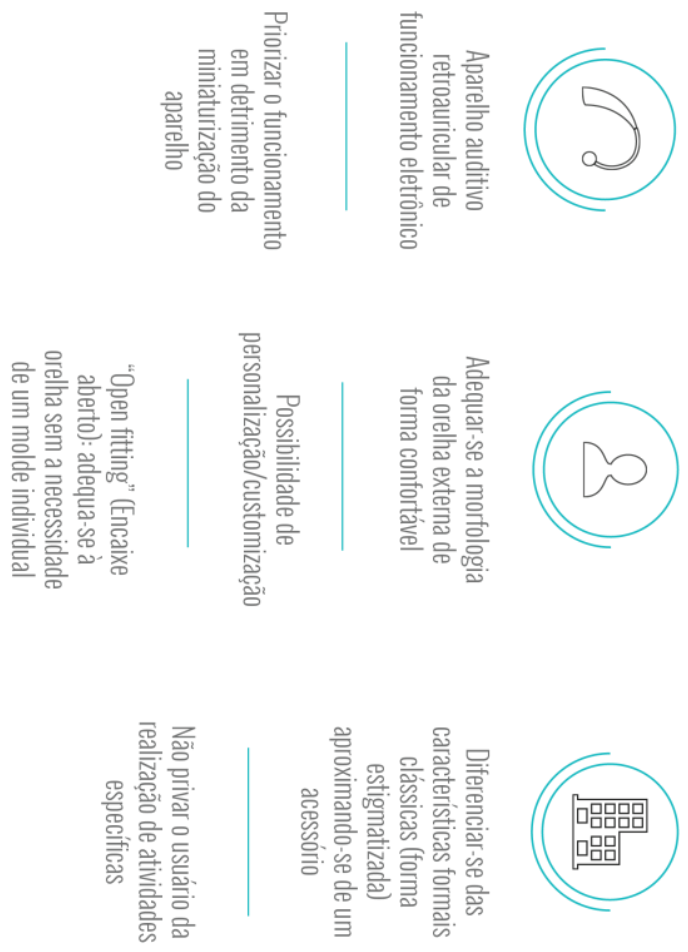

Figura 3- Requisitos de projeto dentro dos blocos de referência

Fonte: a autora

\section{Conclusão}

A perda auditiva afeta uma parcela significativa da população mundial e é uma das deficiências que mais atinge a parcela idosa.

A tecnologia assistiva é um fator essencial para a promoção da participação dos indivíduos deficientes na sociedade, possibilitando o convívio social e consequentemente melhorando a qualidade de vida dos usuários. No entanto, os produtos de tecnologia assistiva, apesar de facilitadores podem ser interpretados como um sinal de incapacidade.

A aplicação do design e da ergonomia em projetos de tecnologia assistiva permite uma abordagem holística e mais humana, em que o todo é levado em consideração, sendo assim analisados não apenas os aspectos funcionais, 


\section{$16^{\circ}$}

ERGODESIGN USIHC CINAHPA

mas o contexto social vivido e principalmente, colocando o ser humano como centro do projeto.

O emprego adequado da ergonomia como ferramenta projetual contribui profundamente para a compreensão da maior parcela de potenciais usuários de um produto. $\mathrm{O}$ desenvolvimento de pesquisas voltadas a este intento é de extrema importância para o bemestar dos usuários na relação com os produtos.

Os requisitos gerados podem nortear o desenvolvimento de produtos que tenham como objetivo a inclusão de deficientes auditivos, associado à melhoria da saúde e qualidade de vida dos mesmos.

Como próximas etapas da pesquisa podem ser pontuadas:

- Verificação dos requisitos de projeto por meio da pesquisa de campo com usuários reais;

- Desenvolvimento de aparelho auditivo utilizando-se dos requisitos gerados;

- Avaliação do aparelho auditivo desenvolvido com usuários reais;

Finalmente, conclui-se que existem oportunidades para o desenvolvimento e aprimoramento de produtos assistivos com base nesta pesquisa e resultados, buscando inclusão e melhoria da auto-estima dos indivíduos.

\section{BIBLIOGRAFIA}

Brasil. Subsecretaria Nacional de Promoção dos Direitos da Pessoa com Deficiência.

Comitê de Ajudas Técnicas. Tecnologia

Assistiva .- Brasília: CORDE, 2009. 138 p.

CALDWELL, Marenda. Going holistic.

Industrial Engineer, Mar. 2009, p. 22. Academic

OneFile, Acessado em 25 jan 2017 $16^{\circ}$ Ergodesign - Congresso Internacional de Ergonomia e Usabilidade de Interfaces Humano Tecnológica: Produto, Informações Ambientes Construídos e Transporte

$16^{\circ}$ USIHC - Congresso Internacional de Ergonomia e Usabilidade de Interfaces Humano Computador

CINAHPA | 2017 - Congresso Internacional de Ambientes Hipermídia para Aprendizagem.
Design for the Whole Population. London:

Springer, 2003.

COLEMAN, Roger. About: Inclusive Design. Design Council. 41p.

DINIZ, Débora. O que é deficiência. São Paulo: Brasiliense. 2007. 80 p.

FROTA, Silvana. Fundamentos em

fonoaudiologia. Rio de Janeiro: Guanabara

Koogan, 2003.

GARDIN, Carlos. O corpo mídia: modos e Moda. In: CASTILHO, Kathia; OLIVEIRA, Ana Claudia (org). Corpo e moda: por uma compreensão do contemporâneo. 2008. pp.75 83.

IEA- International Ergonomics Association.

Definição Internacional de Ergonomia. San

Diego, USA: 2000

LUCAS, Denise Andrade Parracho. Estudo da Evolução dos Acessórios de Moda ao Longo do Século XX e Concepção de um Acessório com Propriedades de Conforto e Design Inovador. 2010. $221 \mathrm{f}$. Dissertação (Mestrado) Curso de Design de Moda, Universidade da Beira Interior, Covilhã, 2010.

MARCONI, Marina de Andrade; LAKATOS, Eva Maria. Fundamentos de metodologia científica. 5. ed. São Paulo : Atlas 2003.

MERINO, Giselle Schmidt Alves Díaz. Metodologia para a Prática Projetual do Design: com base no Projeto Centrado no Usuário e com ênfase no Design Universal. 


\section{$16^{\circ}$}

ERGODESIGN USIHC CINAHPA $16^{\circ}$ Ergodesign - Congresso Internacional de Ergonomia e Usabilidade de Interfaces Humano Tecnológica: Produto, Informações Ambientes Construídos e Transporte

$16^{\circ}$ USIHC - Congresso Internacional de Ergonomia e Usabilidade de Interfaces Humano Computador

CINAHPA | 2017 - Congresso Internacional de Ambientes Hipermídia para Aprendizagem.

2014. 212 f. Tese (Doutorado) - Curso de

Programa de Pós-graduação em Engenharia de

Produção, Centro Tecnológico, Universidade

Federal de Santa Catarina, Florianópolis, 2014.

MUSSI, F. C. Conforto: revisão de literatura.

Rev. Esc. Enf. USP, v.30, n.2, p.254-66, ago. 1996.

NIDCD. National Institute On Deafness And Other Communication Disorders. Hearing Aids. 2016.

PULLIN, Graham. Design meets disability.

Usa: Mit Press, 2009.

RODRIGUES, Patrícia Rocha; ALVES, Lynn Rosalina Gama. Tecnologia assistiva: uma revisão do tema. Holos, v. 6, n. 29, p.170-180, dez. 2013. 